\title{
RONALDO FRAGA E O ESPAÇO METAPROJETUAL COMO FONTE DE CRIATIVIDADE E INOVAÇÃO
}

\author{
Velho, Adriana Galli \\ agalli@ig.com.br \\ Mestranda Design Unisinos
}

Resumo: O presente artigo, através de uma revisão teórica, abordou a concepção do processo de inovação e criatividade tencionados através do metaprojeto. Esta análise iniciou no entendimento das conexões necessárias entre criatividade e inovação, além dos demais elementos que fazem parte desta contextualização, bem como a compreensão do espaço metaprojetual sendo propício, como plataforma de conhecimentos, reflexão e análise de cenários para geração de inovação. Para compreender esta relação foi realizada uma análise do processo de criação do designer de moda Ronaldo Fraga, visto como uma base de pesquisas e projetações de cenários que elevam a moda a novas formas de gerar valor, através da cultura brasileira.

Palavras-chave: Inovação, criatividade, espaço metaprojetual

Abstract: This article, through a literature review, discussed the design of the tensioned creativity and innovation process by metadesign. This analysis started understanding the necessary connections between creativity and innovation, besides other elements that are part of this context as well as understanding the metaprojetual space being suitable as the platform of knowledge, reflection and scenarios analysis to generate innovation. To understand this relationship an analysis of the creation of fashion designer Ronaldo Fraga process was performed, viewed as a foundation of research and design scenarios that elevate fashion to new ways to create value through the brazilian culture.

Keywords: Innovation, creativity, metaprojetual space

\section{INTRODUÇÃO}

Atualmente gerar valor através de um produto ou serviço tornou-se algo que dispende um esforço grande, pois a competitividade entre as empresas está cada vez 
mais acirrada e os impactos econômicos dos avanços tecnológicos também exigem melhorias dos produtos e processos. Esta nova configuração globalizada conduz as organizações a buscarem novas formas de interagir com o mercado, propiciando criarem novas estratégias que permitem desenvolver uma prática que vem se consolidando como a possível panaceia para se manterem vivas e atuantes: a inovação.

A inovação pode ser considerada como um processo de alavancar a criatividade para gerar valor de novas maneiras, por meio de novos produtos, serviços e negócios, conforme Lippi (2003). Desta monta, outra palavra que se desnuda como parceira do inovar é a criatividade que, ao fornecer uma visão de ruptura com o que já existe, quebra paradigmas e evolui ao conceber novidade que, ao gerar o valor econômico, torna-se inovação. Uma das formas que o design opera para possibilitar o processo de inovação é o espaço metaprojetual, onde existe uma intensa reflexão sobre o processo a ser desenvolvido, bem como uma gama ferramental que oportuniza prototipar as ideias a serem concebidas.

A partir destas visões, este artigo pretende compreender, através de um estudo teórico, de que forma o designer Ronaldo Fraga cria suas coleções de moda, transcendendo não apenas o conceito da roupa em si, mas contextualizando outras possibilidades de relação? O método adotado foi a pesquisa bibliográfica, um estudo teórico, pois é "dedicada a reconstruir teoria, conceitos, ideias, ideologias, polêmicas, tendo em vista, em termos imediatos, aprimorar fundamentos teóricos" (Demo, 2000, p. 20). A coleta de informações abrangeu a construção de um referencial apoiado em materiais diversos como livros, revistas, fotografias, sites e a visitação da loja do designer em Belo Horizonte, MG.

Para responder ao problema de pesquisa proposto é traçado um objetivo principal que é compreender o processo criativo do designer Ronaldo Fraga, atrelado aos objetivos secundários, que são:

a) Discutir a relação entre inovação e criatividade

b) Entender a relação do processo criativo e a projetação de cenários

c) Compreender o espaço metaprojetual como gerador de inovação para Fraga

\section{INOVAÇÃO E CRIATIVIDADE: CONEXÕES NECESSÁRIAS}

Existem várias definições para inovação de acordo com autores que focam diferentes áreas de estudo, porém o resultado final não se altera, ela é um processo que contempla invenção, valor econômico e a aceitação pelo mercado.

A seguir o quadro 1 extraído de Lippi (2003) mapeia as diversas bases conceituais que diferentes autores entendem por inovação. 


\begin{tabular}{|c|c|c|}
\hline Autor-Data & Instituição & Conceito \\
\hline $\begin{array}{l}\text { C. K. Prahalad } \\
(1990)\end{array}$ & $\begin{array}{l}\text { Universidade de } \\
\text { Michigan }\end{array}$ & $\begin{array}{l}\text { Inovação é adotar novas tecnologias que permitem aumentar a } \\
\text { competitividade da companhia. }\end{array}$ \\
\hline $\begin{array}{l}\text { Ernest Gundling } \\
(1999)\end{array}$ & $3 \mathrm{M}$ & $\begin{array}{l}\text { Inovação é uma nova ideia, implementada com sucesso, que produz } \\
\text { resultados econômicos. }\end{array}$ \\
\hline Fritjof Capra & $\begin{array}{l}\text { Universidade de } \\
\text { Berkeley }\end{array}$ & As organizações inovadoras são aquelas que se aproximam do limite do caos. \\
\hline Gary Hamel (2001) & (Strategos) & $\begin{array}{l}\text { Inovação é um processo estratégico de reinvenção contínua do próprio } \\
\text { negócio e da criação de novos conceitos de negócios. }\end{array}$ \\
\hline $\begin{array}{l}\text { Giovanni Dosi } \\
(1988)\end{array}$ & Universidade de Pisa & $\begin{array}{l}\text { Inovação é a busca, descoberta, experimentação, desenvolvimento, imitação e } \\
\text { adoçáo de novos produtos, novos processos e novas técnicas organizacionais. }\end{array}$ \\
\hline $\begin{array}{l}\text { Guilherme Ary } \\
\text { Plonski }\end{array}$ & $\begin{array}{l}\text { Instituto de Pesquisas } \\
\text { Tecnológicas }\end{array}$ & $\begin{array}{l}\text { Inovação pode ter vários significados e a sua compreensão depende do } \\
\text { contexto em que ela for aplicada. Pode ser ao mesmo tempo resultado e } \\
\text { processo ou ser associada à tecnologia ou marketing. }\end{array}$ \\
\hline $\begin{array}{l}\text { Joseph Schumpeter } \\
(1982)\end{array}$ & & A inovação caracteriza-se pela abertura de um novo mercado. \\
\hline Vico Mañas (1993) & & $\begin{array}{l}\text { Inovar consiste em nos preocupar com algo que nunca foi feito antes, } \\
\text { ou seja, desenvolver estudos, fazer investimentos, despender tempo em } \\
\text { criatividade, planejamento, controle e coordenação, para, ao final, obtermos } \\
\text { algo totalmente novo. Isso tudo pela necessidade de ser competitivo, de } \\
\text { manter-se vivo ou para manter-se à frente dos concorrentes. }\end{array}$ \\
\hline $\begin{array}{l}\text { Martin Bell e } \\
\text { Keith Pavitt }\end{array}$ & $\begin{array}{l}\text { Universidade de } \\
\text { Sussex }\end{array}$ & $\begin{array}{l}\text { A inovação pode ser vista como um processo de aprendizagem } \\
\text { organizacional. }\end{array}$ \\
\hline $\begin{array}{l}\text { Peter Drucker } \\
(1989)\end{array}$ & $\begin{array}{l}\text { Universidade de } \\
\text { Claremont }\end{array}$ & $\begin{array}{l}\text { É o instrumento específico dos empreendedores, o processo pelo qual eles } \\
\text { exploram a mudança como uma oportunidade para um negócio diferente } \\
\text { ou um serviço diferente. Inovação é o ato de atribuir novas capacidades aos } \\
\text { recursos (pessoas e processos) existentes na empresa para gerar riqueza. }\end{array}$ \\
\hline Price Pritchett & $\begin{array}{l}\text { Consultoria Price } \\
\text { Pritchett }\end{array}$ & $\begin{array}{l}\text { Inovação é como nós nos mantemos à frente do nosso ambiente. As } \\
\text { inovações fora da nossa organização vão acontecer 'quando elas quiserem' - } \\
\text { estejamos prontos ou não. }\end{array}$ \\
\hline $\begin{array}{l}\text { Ronald Jonash e } \\
\text { Tom Sommerlatte } \\
(2001)\end{array}$ & & $\begin{array}{l}\text { Inovação é um processo para alavancar a criatividade a fim de criar valor } \\
\text { de novas maneiras, por meio de novos produtos, novos serviços e novos } \\
\text { negócios. }\end{array}$ \\
\hline Tom Kelley (2000) & Ideo & Inovação é o resultado de um esforço de time. \\
\hline
\end{tabular}

Quadro 1 - Autores importantes e suas definições sobre inovação Fonte: LIPPI; SIMANTOB, 2003.

Observando-se estes conceitos é fácil vislumbrar que a palavra criatividade acompanha várias destas percepções, por exemplo, Jonash e Sommerlatte (2001) abordam a inovação como o processo que alavanca a criatividade e esta permite criar valor através de novos produtos, serviços, processos ou negócios.

Já Schumpeter (1982), ao observar que as longas ondas dos ciclos do desenvolvimento no capitalismo resultam da combinação de inovações, que criam um novo paradigma, passando a impulsionar desta forma o desenvolvimento econômico, cita que a introdução de uma inovação tecnológica substitui antigas opções de consumo, gerando o que o autor economista chama de destruição criativa.

Visto que a criatividade é, com frequência, parte do processo inovador, é importante entender como ela se forma. Weisberg (2006) a define como um conjunto de processos cognitivos que cumprem a função de produzir inovações, pois auxiliam na criação de produtos e serviços novos. Amabile (1996), por sua vez, observa que a criatividade é necessária, porém não é condição para produzir inovações, visto que a 
segunda é um processo que converte a primeira em ideias e, por fim, em produtos e serviços, que possibilitam um grau relevante de novidade.

Compreendendo a criatividade como sendo inerente ao processo de geração de idéias, é fato que ela pode sofrer barreiras, pois está centrada no ser humano e este está exposto a certos bloqueios que podem inibir o potencial criativo. Analisando estas barreiras, segundo Adams (1986), elas podem ser originadas emocionalmente, gerando certos bloqueios, descritos a seguir:

1. Medo de correr risco;

2. Desejo excessivo de ordem;

3. Julgar ao invés de gerar ideias;

4. Incapacidade de incubar ideias;

5. Falta ou excesso de motivação;

6. Realidade ou fantasia.

Vencer estes bloqueios possibilitaria tornar as pessoas sensíveis à criatividade e, por conseguinte, à inovação, pois correr riscos, trabalhar com soluções de problemas complexos pelo viés do caos, pensamento de problem-solving (análise, julgamento e síntese, após o braisntorming), incubação de ideias e trabalhar através das experiências projetadas (manipulação-criatividade-recombinação), liberam o pensamento criativo. $\mathrm{O}$ autor estimula a quebra destes bloqueios através de uma série de exercícios.

Existe também uma forma de trabalhar a criatividade e a possibilidade de inovação, quebrando certos bloqueios e paradigmas, através do pensamento do designer. Este pensamento é desenvolvido, muitas vezes, dentro de um espaço de trabalho metaprojeual que estimula a reflexão, a transferência de conhecimento, a construção de cenários e as formas de se compreender o produto ou serviço, contextualizado a seguir.

\section{O ESPAÇO METAPROJETUAL E O TRABALHO DE RONALDO FRAGA}

O espaço metaprojetual pode ser definido como uma plataforma, um processo ou um percurso. Deserti (2007 p.57), por exemplo, interpreta o percurso metaprojetual como um processo que analisa e interpreta os contextos, bem como age como uma oportunidade de verificar inovações através da investigação de cenários e utilização de criatividade. De Moraes (2010, p. 26) ao iniciar várias análises acerca do caráter de plataforma de conhecimentos que o metaprojeto assume, conclui que:

\footnotetext{
“...o metaprojeto se destaca como disciplina que auxilia o projeto também no âmbito dos conteúdos imateriais ao considerar a comunicabilidade, a interface, a cognição, o valor de estima e o de afeto, o valor e a qualidade percebida e se coloca ainda como mediador na definição do significado do produto (conceito) e da significância (valor)."
} 
Neste sentido o autor busca conectar a realidade complexa contemporânea com a forma como os designers devem agir interligando sistemas e promovendo relações, propondo novas possibilidades de interpretações, através de uma análise e prospecção constante de cenários. Assim, De Moraes (2010) ainda menciona que o metaprojeto propõe uma reflexão que permite se chegar ao conceito, através de interrelações entre o produto e tudo o que o circunda, desde uma comunidade cultural ou um território, bem como um contexto econômico e uma região.

Verificando o que proporciona o ato metaprojetual, nasce a ideia de análise dos trabalhos do designer de moda mineiro Ronaldo Fraga, dentro deste contexto, que é formado pelo antigo curso de estilismo da Universidade Federal de Minas Gerais, com especializações na Parson's School of Design de Nova lorque e Saint Martin School de Londres. Utilizando uma série de metáforas para construir seus trabalhos, foi desenvolvendo uma forma criativa e inovadora de contextualizar suas coleções de roupas. Sua estreia foi sob o título de "Eu amo coração de galinha" e a partir daí não alterou a busca de informações para produção de narrativas que valorizam a história e memória de uma região ou cultura. (Revista $A B C$ Design)

O designer utiliza a moda para revelar um espaço de sentidos culturais e de reflexos de tempo em que já se viveu, se vive e da projeção de novos tempos. Aqui se verifica uma ativa construção de cenários inspirados na literatura, arte e história brasileira, estimulando emoção e convergência dos valores de um povo.

Fraga propõe em seus trabalhos uma nova forma de refletir e criar através da moda, o produto final não é só a roupa em si, artefato com valor utilidade, mas o que ela representa conceitualmente, o significado, este articulado por Krippendorf (2006), remete a pensar este valor como agregador na ruptura com o paradigma do vestir e traz como ferramenta corporal um discurso cultural latente. Para projetar esta intenção, o designer ocupa esta plataforma de conhecimentos e reflexão (De Moraes, 2010) como uma extensão do Brasil, misturando música, croquis, material gráfico, vídeos e as próprias roupas, criando ambientes de exposição para que retorne ao povo aquilo que ele usufruiu como inspiração.

"Meu desejo é que as pessoas entrem ali e encontrem meu playground de criações com todas as referências. Vou privilegiar o registro gráfico: as roupas aparecerão pouco" (Fraga, 2012). Estes ambientes são compostos de instalações que convidam as pessoas a uma imersão no seu processo criativo e na sua visão particular da moda. Além dos aspectos econômicos, ele defende se tratar de setor com forte interface cultural, social e histórica. E ainda uma área que mistura técnica, textura, cores, tecidos e negócios. As figuras 1 e 2 a seguir representam a exposição O Rio São Francisco, realizada em 2009 e que teve um forte apelo de regionalidade, ilustrando os conceitos discutidos neste artigo. 

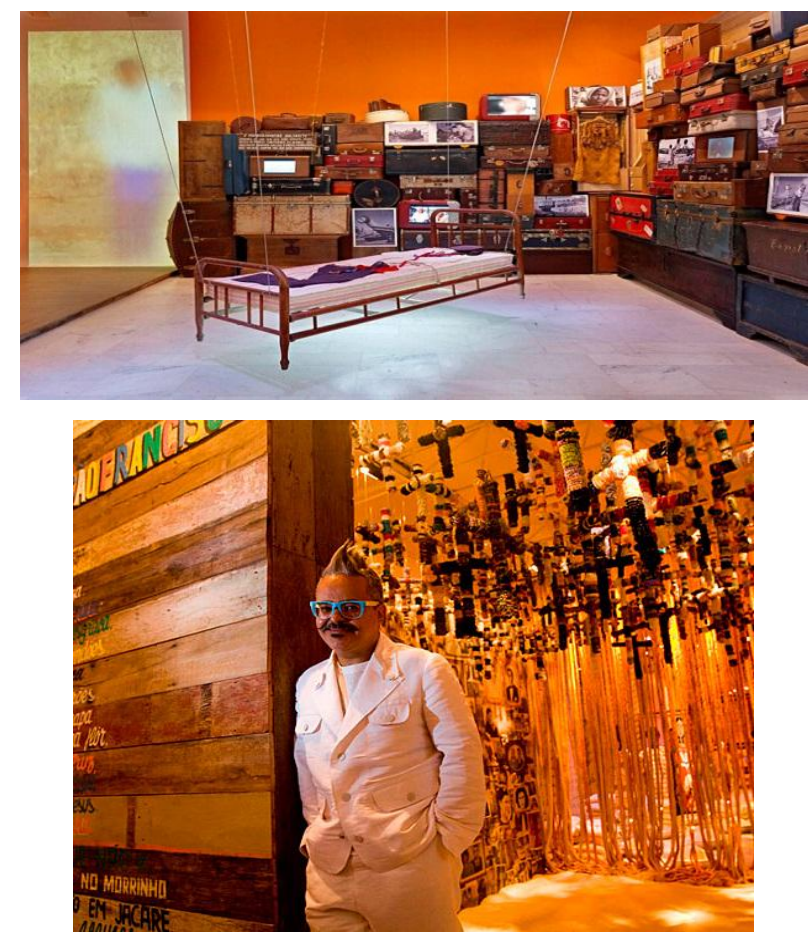

Figura 1 e 2: Exposição O Rio São Francisco (2009) Fonte:

http://saofranciscoronaldofraga.com.br/

Cada desfile ou lançamento se torna uma experiência única que mistura design e conhecimento, alcançando uma perspectiva de significado especial na trajetória da moda, pois quebra o paradigma da roupa como artefato que tem forma e função, através de um valor de uso e utilidade, viabilizando um valor de significado de expressão cultural do povo brasileiro.

\section{CONSIDERAÇÕES FINAIS}

Ao compreender o metaprojeto como uma plataforma de pesquisa, conhecimentos e reflexão, bem como análise de cenários para geração de inovação, se buscou relacionar os projetos do designer Ronaldo Fraga como parte de um espaço metaprojetual, rico para possibilitar o processo de criatividade e inovação. A moda vista pela lente de Fraga parte de uma abordagem de memória e história cultural, resgatada através de pesquisas que são posteriormente separadas em imagens que reproduzem um universo cultural muito peculiar de uma região ou pessoa, traduzindo toda forma de relação que pode ser construída além da coleção de roupas. Assim, segundo Franzato (2011, p. 1) "Metaprojeto é uma atividade transdisciplinar embasada na pesquisa e tensionada para dentro do projeto." O que permite relacionar e compreender a atividade do designer no metaprojeto.

A percepção de experiências extraídas desta trajetória é, em geral, conceituada através de um projeto que envolve uma série de instalações, permitindo um contato reflexivo com a cultura brasileira, pois é expressa em vários outros formatos além do 
ato do vestir, como a música, a arte, o vídeo e as imagens que contam a história de um lugar ou personagem.

É através de uma visão de cenários de passado, presente e prospecção de futuro, trabalhados pelo designer, que vislumbram a possibilidade de inovar e agregar mais valor às coleções de moda criadas por ele. Esta reflexão constante sobre as coleções de Fraga, apoiadas em ferramentas de design que promovem a construção de cenários agregam novas oportunidades criativas ao designer e o remetem a retornar ao projeto e construir novas coleções com mais elementos significativos e inovadores, gerando valor e aceitação no mercado.

Nesta abordagem compreende-se que, Fraga, através de um processo criativo desenvolvido num espaço metaprojetual, cria uma possibilidade de ir além das suas coleções de roupas, transformando estas atividades em instalações que abordam a cultura brasileira e inovam na forma de trazer novas informações aos artefatos, trabalhando de forma sistêmica, antecipando tendências e gerando valor.

Para estudos futuros se entende que a aplicação desta pesquisa pode ser realizada também em formato metodológico com informações qualitativas, através de pesquisas exploratórias, trazendo mais possibilidades de contextualizar os assuntos aqui tratados.

\section{REFERÊNCIAS}

ADAMS, J.L. Conceptual Blockbusting: A guide to better ideas. Perseus Books: Massachusetts. 1986.

CAMPOS, Samira. Ronaldo Fraga: o contador de histórias das passarelas. In: http://www.estilosamiracampos.com.br/gentedeestilo/gde_0030.asp. Acesso em 10 de novembro de 2013.

DE MORAES, D. Metaprojeto o design do design. São Paulo: Blucher, 2010.

DEMO, P. Metodologia do conhecimento científico. São Paulo: Atlas, 2000.

DESERTI, A. IntornoalProjetto: appuntidimerceologia contemporânea. IN CELASCHI, F.; DESERTI, A. (Org). Design \&Inovazzione. Strumenti e pratiche per laricercaapplicata. Roma: Carocci, 2007. MARX, K. O capital. Coleção Os economistas. Volume I, Seção I. São Paulo: Nova Cultural, 1988.

FRANZATO, C. O processo de inovação dirigida pelo design. Um modelo teórico.Redige, v. 2, n. 1, 2011, p. 50-62.

KRIPPENDORFF,K. The semantic turn. A new foundation for design. Boca--Raton: Taylor \& Francis, 2006.

LIPPI, R.; SIMANTOB, M. Guia valor econômico de inovação nas empresas. São Paulo: Globo, 2003.

MABILE, T.M. Creativity in context. Westview Press, 1996

SCHUMPETER, J. A. A teoria do desenvolvimento econômico. São Paulo: Abril Cultural, 1982. 
WEISBERG, R. W. Modes of expertise in creative thinking: evidence from case studies. In: Ericsson, K.A. et al (Org). The Cambridge handbook of expertise and expert performance.New York: Cambridge University Press, 2006. p. 761-787.

\section{Entrevista:}

Revista ABC Design abril/maio/junho 2013

Meio Eletrônico:

FRAGA,

$R$.

Disponivel

em:

impresso.em.com.br/app/noticia/cadernos/.../interna_cultura,53479/acesso em 09 de novembro de 2013.

FRAGA, R. Disponível em: http://saofranciscoronaldofraga.com.br/ acesso 09 de novembro de 2013. 